\title{
îे \\ Pluralismo metodológico, incomensurabilidade e o status científico do conhecimento tradicional
}

Hugh LAGEY

\begin{abstract}
电
RESUMO

Os valores culturais podem ter um impacto construtivo nas práticas científicas e levar a variações culturais legítimas nas abordagens sobre as mesmas. Segue-se que o conhecimento tradicional ou indígena não precisa opor-se ao conhecimento científico, e somente a investigação caso-a-caso pode estabelecer se as credenciais cognitivas de itens particulares do conhecimento tradicional são adequadas ou deficientes. Com base em uma análise de como as estratégias metodológicas podem tanto competir quanto complementar umas às outras, eu argumento que o que há de defensável na noção de incomensurabilidade de Thomas Kuhn e a possibilidade da solidez do status científico do conhecimento tradicional compartilham da mesma fonte.
\end{abstract}

Palavras-Ghave • Pluralismo metodológico. Incomensurabilidade. Kuhn. Conhecimento tradicional. Imparcialidade. Neutralidade. Estratégias metodológicas.

\section{O PLURALISMo METOdolóGigo}

A ciência deveria ser pensada como uma investigação empírica sistemática, sensível ao ideal de imparcialidade, conduzida mediante o uso de quaisquer estratégias metodológicas que sejam apropriadas à obtenção do entendimento dos objetos investigados (cf. Lacey, 2008a, 2010).

Assim concebida, a ciência é compatível com o pluralismo metodológico, com a visão de que (i) a pesquisa fecunda - pesquisa que leva a resultados de acordo com a imparcialidade, por conseguinte, a construção e a consolidação de teorias que manifestam os valores cognitivos com alto grau de respeito aos domínios específicos do fenômeno - pode ser conduzida mediante o emprego de diferentes tipos de estratégia, e de que (ii) a investigação de diferentes tipos de objetos e a adequada capacidade de responder à imparcialidade podem, realmente, requerer a adoção de tipos de estratégias fundamentalmente diferentes. Entretanto, ao longo da tradição científica moder- 
na, o pluralismo metodológico raramente foi considerado com seriedade. Para muitos, a metodologia científica tem-se limitado à utilização de estratégias da abordagem descontextualizada (estratégias AD, ver $§$ 1.2). No entanto, argumentei não apenas que a conduta da ciência é compatível com o pluralismo metodológico, mas também que deve cultivar ativamente a utilização de uma pluralidade de estratégias incluindo algumas que não podem ser reduzidas às estratégias AD (cf. Lacey, 2010, 2011b). Um importante componente do meu argumento é que, embora as estratégias AD sejam suficientes para a pesquisa que gera inovações tecnocientíficas e que explica a sua eficácia, as pesquisas sobre, por exemplo, riscos e alternativas, que são relevantes para legitimar a implementação de inovações, requerem o uso de estratégias não AD, as quais levam em conta o contexto ecológico e social do fenômeno (cf. Lacey, 2008b, 2008c, 2009). Portanto, a pesquisa dirigida segundo as estratégias AD passa a ser entendida apenas como uma abordagem da ciência, uma abordagem que, embora seja importante e indispensável (cf. Lacey, 2012), tem resultados que podem (e, às vezes, devem) ser utilizados livremente sob quaisquer estratégias potencialmente fecundas, porém, isso não é suficiente para investigar todos os fenômenos que importam no mundo da experiência vivida.

Os valores éticos/sociais/culturais influenciam quais objetos (fenômenos, possibilidades) são prioritários para a investigação científica e, por conseguinte, quais estratégias precisam ser adotadas no projeto de pesquisa. $\mathrm{O}$ modelo de interação entre ciência e valores, proposto em Lacey (2008a, 2010) e resumido em Lacey (2010, Introdução), o qual permite que a adoção de uma estratégia possa ter relações de reforço mútuo com a sustentação de valores particulares, mostra que não é solapada a possibilidade de obter-se resultados de acordo com a imparcialidade. À luz disso, não deveria ser descartado a priori (i) que os valores culturais (diferentemente dos valores ocidentais atualmente hegemônicos) podem ter impacto construtivo sobre quais estratégias são adotadas na pesquisa, e que pode haver variações legítimas de base cultural nas abordagens da prática científica; e (ii) que o conhecimento tradicional e indígena pode não estar em oposição ao conhecimento científico, mas sim aberto à interpretação como resultado das práticas de aquisição de conhecimento que empregam estratégias AD (ver §4). ${ }^{\mathbf{1}}$

1 Os ideais de imparcialidade e de neutralidade, introduzidos nesta seção, e a noção de estratégia metodológica foram amplamente discutidos em vários artigos publicados em Scientiae Studia (Lacey, 2008b, 2008d, 2009, 2011b, 2012), bem como em Lacey (2008a, 2010). Convém que o leitor se dirija a esses trabalhos a fim de obter mais detalhes sobre essas e outras noções introduzidas no parágrafo seguinte e alhures, a saber: estratégias AD, as razões para a sua adoção quase exclusiva, possibilidades descontextualizadas, tecnociência, os valores do progresso tecnológico e suas pressuposições, os valores cognitivos e minha explicação da interação entre ciência e valores. 
Pluralismo metodológigo, incomensurabilidade e o status científico...

1.1 A incomensurabilidade e o status Gientífico do GONHEGimento tradicional

O pluralismo metodológico permite que diferentes estratégias possam tanto competir quanto complementar umas às outras. A elaboração de como isso ocorre subjaz ao meu argumento a favor da possibilidade do conhecimento tradicional ter status científico legítimo. Isso também serve para esclarecer as ideias acerca da incomensurabilidade das teorias desenvolvidas no interior de paradigmas incompatíveis (cf. Kuhn, 1970). Um paradigma incorpora uma estratégia e uma estratégia incorpora um "léxico estruturado" (cf. Kuhn, 2000). ${ }^{2}$ Vou argumentar que características das estratégias incorporadas em paradigmas concorrentes subjazem à incomensurabilidade das teorias desenvolvidas no interior deles. Aquilo que é defensável na incomensurabilidade e a possibilidade do status científico legítimo do conhecimento tradicional compartilham da mesma fonte.

\subsection{A COMPLEMENTARIDADE DAS ESTRATÉGIAS}

De acordo com o pluralismo metodológico, a investigação de diferentes tipos de objetos e possibilidades requer a adoção de diferentes tipos de estratégias. Sob as estratégias AD, as teorias são restringidas para representar o fenômeno como sendo gerado por estrutura, processo, interação e lei subjacentes, dissociados de seus contextos humanos, sociais e ecológicos. Os dados quantitativos, amiúde aqueles obtidos pelas operações de medida em espaços experimentais, são de grande importância, de modo que a pesquisa conduzida sob estratégias AD produz teorias que encapsulam as possibilidades descontextualizadas das coisas (ver referências na nota 1). As estratégias aristotélicas, em contraste, envolvem fenômenos relacionados aos seus respectivos lugares no cosmo. Suas categorias teóricas refletem metáforas orgânicas, os dados relevantes podem vir dos fenômenos observados no mundo da experiência vivida, e empregam, por exemplo, categorias sensoriais e teleológicas comuns. As estratégias agroecológicas também são diferentes. Elas não se dissociam do contexto e da dimensão social, humana e ecológica das coisas. Seu foco recai sobre os agroecossistemas produtivos e sustentáveis, seus constituintes (sementes, plantas etc.) e as "interações complexas entre pessoas, tipos de cultivo, solo e criação de animais" (Altieri, 1987, p. xv), cujas possibilidades não estão reduzidas às estratégias AD. ${ }^{3}$

2 Para uma interpretação detalhada dos textos de Kuhn sobre "paradigma” e suas noções sucessoras ("matriz disciplinar", "léxico estruturado"), e sobre as mudanças nas posições de Kuhn ao longo dos anos, ver Hoyningen-Huene (1993) e Sankey (1997). Sobre as relações entre minha "estratégia” e o "paradigma” de Kuhn, ver Lacey (1999, p. 261). 3 Para uma caracterização detalhada das estratégias agroecológicas, e da evidência de que as pesquisas conduzidas a partir delas têm sido frequentemente fecundas, (cf. Lacey, 2006, cap. 5; 2010, cap. 2, 4; Embrapa, 2006; Tavares, 2009). 
A escolha da estratégia adotada em um projeto de pesquisa é (explícita ou implicitamente) inseparável da delimitação da esfera dos fenômenos considerados de interesse para a investigação e dos tipos de possibilidades que se deseja encapsular. Os compromissos de valor e os compromissos metafísicos influenciam o que é considerado de interesse, e aqueles que adotam uma estratégia para moldar suas pesquisas podem fazer assim, em parte, por causa de tais compromissos, embora estes não proporcionem boas razões para que esse tipo de estratégia seja adotado em todas as pesquisas científicas (ver 33 ). Isso tem implicações no modo de entender e estimar o uso quase exclusivo das estratégias AD na ciência moderna. As pesquisas conduzidas no interior da estratégia AD vêm sendo extraordinariamente fecundas, e é razoável esperar que continue sendo assim, o que é hoje amplamente valorizado em grande parte porque tem instruído a geração de inovações tecnológicas originais. Entretanto, as pesquisas conduzidas sob diferentes tipos de estratégias, desde que sejam (como as pesquisas dirigidas segundo as estratégias AD) fecundas, tornam-nos aptos a identificar diferentes classes de possibilidades. Por exemplo, adotando as estratégias AD da biotecnologia pode-se identificar as possibilidades de maximização da produção de colheitas sob certas condições - uso de fertilizantes, técnicas de manejo de pestes e ervas daninhas, água, maquinário, linhagens das sementes etc. - que podem ser largamente replicadas, ao passo que nas estratégias da agroecologia são identificadas as possibilidades de produzir colheitas de um modo que as pessoas das regiões de produção tenham acesso a uma dieta bem balanceada, em um contexto que intensifica a atividade coletiva local e o bem-estar, e que sustenta o meio ambiente. Em geral, as possibilidades encapsuladas pelas teorias desenvolvidas sob diferentes estratégias sobrepõemse, no máximo, por sugerirem que um "entendimento completo" dos fenômenos do mundo da experiência vivida não pode ser obtido (mesmo a princípio) se for submetido a apenas um dos tipos de estratégias (cf. Lacey, 2009, 2011a). Essa é a base para a complementaridade das estratégias.

\section{A GOMPETIÇÃo ENTRE AS ESTRATÉGIAS: INGOMENSURABILIDADE}

As estratégias também competem. Conduzir a pesquisa científica a partir de uma estratégia pode ser incompatível com a sua condução (no mesmo contexto histórico e social) a partir de outra. Eu sugiro que o que Kuhn chama de "incomensurabilidade" (cf. Kuhn, 1970, p. 150; Hoyningen-Huene, 1993, p. 208-12) deriva fundamentalmente da incompatibilidade prática entre estratégias concorrentes.

Kuhn usa a metáfora dos "mundos diferentes" para captar essa incompatibilidade. Nela, o "mundo" científico está ligado a uma "forma de vida", suas requisitadas 
habilidades, hábitos, expectativas e o sentido daquilo que é possível, suas estruturas organizacionais, e seus modos de engajamento ativo na pesquisa. 4 Ele diz que cada paradigma define seu próprio "mundo" diferente. As prescrições de estratégias diferentes, no que diz respeito às restrições nas teorias e na seleção de dados, são praticamente incompatíveis; elas estruturam "modos incompatíveis de vida em comunidade [científica]" (Kuhn, 1970, p. 94). Contudo, os "mundos" diferentes estão todos localizados no "mundo" sócio-histórico compartilhado ("mundo da experiência vivida"), cujos fenômenos são capazes de serem entendidos, e suas possibilidades antecipadas, usando as teorias desenvolvidas sob uma estratégia, que informa as práticas (cf. Lacey, 1999, p. 149-54). Mas uma estratégia não pode ser adotada coerentemente em um "mundo" que não é particularmente definido por ela, de modo que as estratégias competidoras (estratégias que pertencem a paradigmas diferentes) não podem ser adotadas no mesmo "mundo".

Aqui, a metáfora do "mundo" é enganosa. É difícil que dois sistemas de ampla abrangência possam coexistir simultaneamente, o que sugere que as estratégias competidoras não podem ser concomitantemente adotadas (por muito tempo) no mundo da experiência vivida mesmo por grupos diferentes. De fato, as estratégias AD e as estratégicas aristotélicas não podem ser simultaneamente adotadas para explicar e predizer os fenômenos do mundo da experiência vivida (ver §3). Talvez enganado por sua metáfora, tratou Kuhn toda competição estratégica como se ela fosse a competição entre as estratégias AD e as estratégias aristotélicas, e assim ele não reconheceu os modos pelos quais as estratégias competidoras podem ser complementares (ver $\S_{1.2}$ ). As estratégias AD e, por exemplo, as estratégias agroecológicas podem ser adotadas concomitantemente, mas não no mesmo contexto social. Eu prefiro a metáfora de Wittgenstein dos “jogos”. As pesquisas biotecnológica e agroecológica são "jogos” como o futebol e o rugby - que não podem ser jogados ao mesmo tempo nos mesmos campos, mas eles podem ser jogados (sob certas circunstâncias) simultaneamente em campos diferentes. Evidentemente, o mundo da experiência vivida é cheio de tensões e certamente existem tensões associadas com a adoção simultânea de estratégias competidoras. São diferentes as interações com os objetos naturais exigidas para obter tipos prescritos de dados para que se possa interferir nas condições necessárias à obtenção dos tipos de dados prescritos por outra estratégia. Por exemplo, as interações envolvidas na investigação da produção de cultivos como uma função de métodos amplamente replicáveis podem interferir na manutenção da estabilidade ecológica local; e engajar-se no experimento envolve modificação dos cenários “naturais”, cuja ob-

4 Ver Rouse (1987). Aqui (e alhures no artigo), eu articulo as posições inspiradas em Kuhn de que faço uso, mais do que interpreto a própria posição de Kuhn (ver nota 2). 
servação fornece dados sob algumas estratégias. Mesmo assim, o mundo da experiência vivida, por fornecer (mais ou menos) espaços separados para a prática, por exemplo, tanto da agricultura dependente de biotecnologia quanto da agroecologia, pode também fornecer espaços nos quais as estratégias necessárias para a pesquisa que respectivamente informa essas práticas possam também ser adotadas, mas não simultaneamente nos mesmos espaços.

\subsection{A incomensurabiLidAdE SEMÂNTICA}

Quando as prescrições estratégicas são praticamente incompatíveis, frequentemente os itens relevantes de seus respectivos léxicos não podem ser intertraduzidos e, assim, as propostas teóricas expressas usando os léxicos estruturados de estratégias diferentes, bem como suas negações, podem não ter qualquer implicação lógica entre si. Isso é a incomensurabilidade semântica. Ela subjaz ao fenômeno da incomunicabilidade que Kuhn considera estar frequentemente presente entre os adeptos de paradigmas incompatíveis. Uma vez que aprender o significado de termos teóricos requer a "participação em um modo de vida da comunidade científica”, aqueles que são fluentes no emprego de uma estratégia podem falhar em entender as teorias desenvolvidas sob uma estratégia incompatível. É uma questão de disputa o alcance do fenômeno da incomensurabilidade semântica, até onde existe incomunicabilidade genuína entre aqueles que adotaram respectivamente estratégias diferentes. ${ }^{5}$

Quando a incomensurabilidade semântica prevalece, a incompatibilidade estratégica tende a não se manifestar em direta contradição com os postulados das teorias investigadas sob as respectivas estratégias. Isso não impede, contudo, que possam surgir contradições se tais teorias são utilizadas conjuntamente para fornecer explicações teóricas dos fenômenos do mundo compartilhado da experiência vivida. Quando os fenômenos são descritos usando categorias do léxico do idioma comum, as descrições são frequentemente acordadas pela maioria das pessoas independentemente de suas orientações teóricas. As teorias científicas são usadas para fornecer descrições adicionais dos fenômenos, as quais servem a fins explanatórios e preditivos; e, fazendo-se isso, os objetos descritos em idioma comum são identificados com os objetos teoricamente articulados. As contradições podem ser geradas (no léxico do idioma comum expandido para incorporar os léxicos teóricos) nas tentativas de usar teorias desenvolvidas sob estratégias diferentes (por exemplo, uma que emprega categorias de quantidade e lei, e outra que emprega categorias sensoriais e teleológicas), para explicar os

5 Ver algumas referências na nota 2. Kuhn, por si mesmo, estreitou consideravelmente o que ele alegava ser o escopo da incomensurabilidade semântica em seus escritos após A estrutura das revoluções científicas (cf. Kuhn, 2000). 
mesmos fenômenos da experiência comum e fazer predições sobre os mesmos. Por exemplo, o enunciado "os corpos caem na Terra por causa da atração da Terra de acordo com a lei da gravidade" não contradiz diretamente "corpos caem por causa da tendência a moverem-se para seus lugares naturais", porém, afirmar que os corpos no mundo da experiência vivida caem de acordo com ambos enunciados envolve uma contradição que pode ser explicitada quando os léxicos das duas teorias são incorporados ao léxico do discurso ordinário (cf. Lacey, 1999, p. 161-7). Além disso, a incomunicabilidade referida nos parágrafos anteriores é, com frequência, mais pronunciada nas contradições entre as visões de mundo que subjazem a suposições de longo alcance sobre o caráter e as possibilidades gerais das coisas que são mobilizadas para sustentar a adoção de estratégias, ou legitimar aplicações de seus produtos teóricos nos projetos práticos (cf. Lacey, 2011a). As suposições metafísicas conflitantes estavam, por exemplo, envolvidas na competição do século xvıI entre as estratégias galileanas e as aristotélicas, e reforçaram a incomunicabilidade entre os adeptos dessas respectivas estratégias.

Kuhn distingue a incomensurabilidade semântica da incomensurabilidade metodológica. De modo a evitar as ambiguidades que frequentemente surgem, e antes de proceder à explicação da última noção, será útil introduzir uma ampla digressão (cuja pertinência ficará clara ao longo do restante do artigo) sobre as noções de "aceitação"/ "rejeição" de uma teoria т e os seus diferentes sentidos. ${ }^{6}$

\subsection{Digressão Sobre A AGeitaçÃo DE UMA teoria}

Distingo quatro sentidos de "aceitar T":

Aceitar $_{1} T$ = julgar que $T$ fornece entendimento de um domínio específico de fenômenos $D$ (abreviação: $\operatorname{aceitar}_{1} T$ de $D$ ).

Aceitar $_{2} T$ = julgar que $T$ é racionalmente preferível a competidoras com a finalidade de guiar a investigação em curso.

Aceitar $_{3} T=$ julgar que $T$ é a teoria geral mais abrangente não falseada disponível.

Aceitar $_{4} T$ = endossar $T$, ou seja, julgar que $T$ é suficientemente bem confirmada para justificar o seu papel na orientação da ação prática.

Aceitar ${ }_{1}$ é o sentido de "aceitar" no qual a aceitação de uma teoria deveria idealmente estar de acordo com a imparcialidade: $\operatorname{aceitar}_{1} T$ de $D$ coaduna-se com a impar-

$6 \mathrm{Meu}$ argumento precisa ser complementado com uma detalhada análise de "teoria" e das variedades de teorias científicas que podem ser usadas. 
cialidade se e somente se $T$ manifesta os valores cognitivos à luz dos dados empíricos disponíveis obtidos pela observação dos fenômenos de $D$, supondo-se que tem sido conduzida toda pesquisa que poderia levar à rejeição ${ }_{1}$ de $T$, proposta no curso de discussão crítica extensiva (cf. Lacey, 2010, cap. 1). Aceitar ${ }_{2} T$ pressupõe que $T$ foi aceita $_{1}$ para um conjunto de fenômenos, de modo que quanto maior o conjunto, maior seu poder explanatório (ver $§ 2.3$ ).

Para alguns filósofos da ciência (por exemplo, Popper), a pesquisa científica desdobra-se mediante esforços para falsear a teoria geral mais abrangente à disposição; e a história da ciência dá origem à sequência de teorias gerais falseadas, cada uma substituída por uma sucessora mais abrangente. Para eles, aceitar ${ }_{3}$ é o sentido fundamental

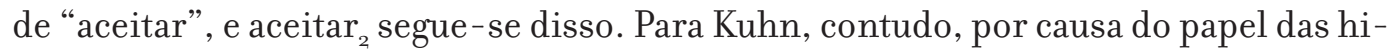
póteses auxiliares na mediação entre os postulados teóricos e os dados empíricos, nenhuma teoria geral é falseável. Isso explica a introdução dos valores cognitivos nas análises realizadas por Kuhn acerca da racionalidade da avaliação de teorias, em vez de usar as regras dedutivas de Popper ou as regras indutivas dos positivistas lógicos. ${ }^{7}$ Então, a pesquisa científica revela-se como "solução de quebra-cabeça”, tenta completar os detalhes de um paradigma ou explorar o poder explanatório e preditivo (e a manifestação dos outros valores cognitivos), que se torna possível pela estratégia do paradigma; e, então, quando os recursos de um paradigma foram exauridos, segue-se adiante com um novo paradigma que pode resolver as "anomalias" do anterior. Assim, aceitar $_{2}$ é fundamental, e aceitar 3 não tem nenhuma relevância de fato.

Nem Popper nem Kuhn tiveram muito interesse na ciência aplicada. Não pensaram que ela era racionalmente relevante para as estratégias que são adotadas na pesquisa; tampouco devotaram atenção ao fato de que o estoque do conhecimento científico consolidado, frequentemente justificado por suas aplicações bem-sucedidas, continua a crescer, a despeito da transformação das teorias gerais que foram rejeita$\operatorname{das}_{2}$ (ou rejeitadas ${ }_{3}$. Popper e Kuhn refletem uma visão da pesquisa científica que é comumente adotada, especialmente entre os principais contribuidores dos desenvolvimentos teóricos, e ela tem o seu lugar próprio. Não obstante, penso que está entre os objetivos fundamentais da pesquisa científica expandir o estoque do conhecimento científico consolidado (de fenômenos predominantes do mundo da experiência vivida, e relevantes para informar as práticas humanas), e tal conhecimento de domínios particulares dos fenômenos é tipicamente expresso em teorias que são aceitas ${ }_{1}$ nesses domínios em concordância com a imparcialidade.

7 Nos meus escritos, afirmei repetidamente que os valores cognitivos, os quais são independentes de quaisquer valores sociais e éticos (permitindo algum desenvolvimento histórico), podem e devem ser compartilhados através das estratégias, mas, como Koide (2011) indica justamente, não ofereci um argumento convincente para essa afirmação. $\mathrm{O}$ assunto requer mais atenção crítica. 
A aceitação ${ }_{2}\left(\right.$ aceitação $_{3}$ ) é sempre provisória no sentido de que existem boas razões para defender que a pesquisa adicional levará à rejeição ${ }_{2}\left(\right.$ rejeição $_{3}$ ) de quaisquer teorias gerais que são ou foram consideradas, pois - tal como atestado pela história da ciência, mesmo com as teorias mais firmemente aceitas $_{2}$, por exemplo, a de Newtonos limites de seu poder explanatório e preditivo são suscetíveis a tornarem-se evidentes com a investigação de novos domínios de fenômenos. A aceitação ${ }_{1}$ não é provisória no mesmo sentido. $T$ é aceita de $_{1} D$ em concordância com a imparcialidade somente

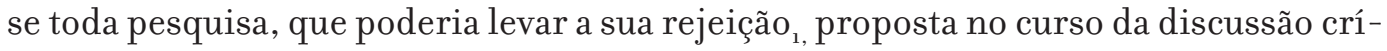
tica ampliada, tenha sido conduzida de modo que a investigação adicional seria somente uma duplicação da pesquisa já adequadamente conduzida. Assim, embora permaneça logicamente possível que a pesquisa subsequente possa levar a sua rejeição, não existe nenhuma razão efetiva para antecipar que esse seria o caso, e existe boa razão para antecipar que ela não levaria a isso. Disso segue-se que sendo $T$ apropriadamente aceita de $D$, ela não é afetada pela rejeição ${ }_{2}\left(\right.$ rejeição $\left._{3}\right)$ subsequente de T. O estoque de conhecimento científico expande-se a despeito da (e por causa da) mudança de teorias aceitas ${ }_{2}$. Quando $T$ é propriamente aceita ${ }_{1}$ de $D$, isto é, quando manifesta os valores cognitivos em alto grau nos fenômenos de $D$, então resume com sucesso as possibilidades relevantes desses fenômenos, independentemente de qual teoria geral posterior possa vir a ser aceita ${ }_{2}$ em lugar de T. O próprio Kuhn concorda com tal posição:

Na medida em que a teoria newtoniana foi verdadeiramente uma teoria científica [isto é, uma teoria de certos fenômenos propriamente aceita ${ }_{1}$ apoiada pela evidência, ela ainda permanece assim. Somente afirmações extravagantes a favor da teoria - afirmações que nunca foram propriamente partes da ciência [isto é, afirmações que não diziam respeito aos fenômenos pelos quais a teoria foi solidamente aceita ] - podem ter sido demonstradas como erradas por Einstein. Livre dessas extravagâncias meramente humanas, a teoria de Newton nunca foi, nem pode ser, desafiada (Kuhn, 1970, p. 99).

Isto é fundamental para o desenvolvimento da ciência aplicada.

A aceitação ${ }_{4}$, que não desempenha papel algum no argumento deste artigo, é mencionada somente para fins de completude. Ela não é considerada seja por Popper, seja por Kuhn, pois sua pertinência surge somente quando se faz a pergunta: uma alegação - por exemplo, de que uma inovação proposta é eficaz, de que ela não tem nenhum risco significativo, de que não existe inovação alternativa séria - é suficientemente bem confirmada para justificar seu lugar dentre as alegações usadas para legitimar uma aplicação? A aceitação ${ }_{1}$ basta para a aceitação ${ }_{4}$, e as alegações típicas sobre a eficácia das inovações científicas são propriamente aceitas ${ }_{1}$. Contudo, nos mo- 
mentos de tomada de decisão sobre a legitimação de inovações, que são tipicamente alegações sobre benefícios projetados, riscos e alternativas, elas não podem ser aceitas ${ }_{1}$ de acordo com a imparcialidade; elas somente podem ser endossadas (cf. Lacey, $2008 \mathrm{~d}, 2011 \mathrm{~b}$ ), e os valores éticos/sociais assim como os valores cognitivos estão em jogo nesse ato do endosso. 0 papel do pluralismo metodológico na pesquisa que leva à tomada de decisão sobre os endossos e o modo como essa pesquisa pode (e deve) ser sensível ao ideal da imparcialidade são discutidos em outro lugar (cf. Lacey, 2011b).

\subsection{A incomensurabilidade metodológica}

Existem várias interpretações da noção de "incomensurabilidade metodológica", que para alguns pode ser caracterizada aproximadamente como segue: "Os padrões metodológicos para avaliação de teorias são diferentes em diferentes paradigmas, nos quais os valores cognitivos e as prescrições estratégicas tendem a ser reunidos indiscriminadamente sob 'padrões metodológicos', e nos quais é dito que a adoção de tais padrões, incluindo os valores cognitivos, reflete as contingências sociais e culturais". Porém, penso que o que é defensável na noção de "incomensurabilidade metodológica" é bem representado pela conjunção das duas seguintes asserções:

(i) Os graus de manifestação dos valores cognitivos em teorias ( $T_{1}, T_{2}$ etc.) desenvolvidas respectivamente sob estratégias concorrentes não podem (geralmente) ser comparados, de modo que o conflito teórico que perpassa as estratégias incompatíveis não pode ser racionalmente resolvido de acordo com o modelo:

$M_{1}$ : Onde $T_{1}$ e $T_{2}$ concorrem, $T_{1}$ é preferível racionalmente a $T_{2}$ se e somente se, depois que a pesquisa apropriada foi conduzida, $T_{1}$ manifesta todos (a maioria) os valores muito mais do que $T_{2}$.

(ii) A escolha entre estratégias concorrentes é subdeterminada por considerações que repousam somente sobre os valores cognitivos.

Para Kuhn, o modelo $M_{\imath}$ é geralmente adequado para julgar a aceitação ${ }_{2} /$ rejei- $^{-}$ ção ${ }_{2}$ de teorias dentro da "ciência normal", na qual as estratégias não são contestadas pela comunidade de pesquisa, e as limitações sobre sua relevância surgem somente em tempos de "revolução científica". A fim de compreender por que $M_{\imath}$ é incapaz de resolver conflitos teóricos que atravessam as estratégias, considera-se o valor cognitivo da adequação empírica. Ela recebe uma interpretação concreta, que permite que o grau de sua manifestação em uma teoria seja "medido" somente no contexto de uma estratégia que prescreva os tipos de dados que deveriam ser postos em contato com certos 
tipos de teorias. Uma teoria não é só empiricamente adequada, mas empiricamente adequada com respeito aos tipos específicos de dados de um domínio específico de fenômenos, descritos mediante o uso das categorias de um léxico específico. Contudo, os tipos relevantes variam com a estratégia. Desse modo, nós não podemos (geralmente) comparar a adequação empírica por meio das estratégias, pois a única comparação relevante ocorre quando os dados que uma teoria deveria "encaixar" constituem um subconjunto daqueles que outra teoria deveria "encaixar". Conclusões similares podem ser extraídas de outros valores cognitivos (poder explanatório, consistência etc.) que concernem às relações entre a teoria e os dados (cf. Lacey, 2008a, cap. 3). Assim, $M r$ aplica-se (geralmente) apenas à comparação de teorias desenvolvidas sob a mesma estratégia.

Outro modelo, $M_{2}$, é necessário para que possa existir a escolha racional entre teorias fundamentais concorrentes $T_{1}$ e $T_{2}$ que, em tempos de revolução científica, são geradas respectivamente sob estratégias concorrentes $E_{1}$ e $E_{2}$ (cf. Lacey, 1999, p. 229):

M2: $T_{1}$ é racionalmente escolhida se e somente se $T_{1}$ manifesta sobremaneira os valores cognitivos interpretados de acordo com as prescrições para restringir teorias e selecionar dados de $E_{1}$, e $T_{2}$ manifesta (ou chegou a manifestar) muitos deles em um baixo grau interpretado de acordo com as prescrições de $E_{2}$; e $E_{1}$ exibe uma promessa de fecundidade continuada enquanto $E_{2}$ cessou de ser muito fecunda, isto é, os esforços em $E_{2}$ para gerar teorias que manifestam os valores cognitivos - apoiados por condições materiais e sociais apropriadas - não são (ou deixaram de ser) bem-sucedidas.

Quando se aplica $M_{2}$, aceitar ${ }_{2} T_{1}$ é inseparável do descarte de $E_{2}$ como estratégia racionalmente digna de adoção e, portanto, da exclusão da esperança de encontrar-se um sucessor "melhor" para T2 mediante pesquisa adicional conduzida sob E2. Não existe qualquer lugar para o pluralismo metodológico na "ciência normal". Para Kuhn, resolver as anomalias que surgiram sob $E_{2}$, e exibir a promessa de proficuidade, é suficiente não somente para descartar E2, mas também para adotar $E_{1}$ como moldando a pesquisa em andamento. Kuhn não é um relativista; para ele, as transições "revolucionárias" - escolha de teorias, feita de acordo com $M_{2}$ e acompanhada pela adoção de $E_{1}$ são racionais.

Julgamentos seguros apropriadamente feitos de acordo tanto com $M_{1}$ quanto com M2 são independentes (logicamente) de valores culturais, éticos e sociais, incluindo todas as considerações pertencentes ao valor de aplicações do conhecimento obtido, e aos interesses das instituições sociais que fornecem o suporte material necessário para 
que a pesquisa científica seja conduzida. Contudo, fazer julgamentos seguros pode depender causalmente de sustentar valores sociais particulares, pois, para fazê-los, é preciso ter desenvolvido as habilidades cognitivas necessárias, estar adequadamente localizado, ser capaz de atrair suporte material, ou estar interessado em fazer pesquisa sobre aquilo em que eles estão baseados. É importante distinguir os fundamentos sobre os quais tais julgamentos são racionalmente baseados dos fatores que explicam as condições disponíveis para sua realização (cf. Lacey, 1999, p. 231-36; 2008d). O último, mas não o primeiro, pode incluir valores sociais e culturais; somente o primeiro concerne à racionalidade do desdobramento da ciência (cf. Lacey, 2010, cap. 2). Lembre-se que aceitar ${ }_{2} T$ pressupõe que, para vários $D, T$ foi aceita ${ }_{1}$ de $D$. De acordo com Kuhn, a tradição científica, desenvolvendo-se segundo essa imagem racional, determina quais domínios de fenômenos serão investigados, frequentemente são fenômenos experimentais criados com o fito de escolher entre teorias no interior da ciência normal de acordo com $\mathrm{M}_{1}$; e esses fenômenos, por sua vez, frequentemente tornam-se as anomalias que proporcionam a ocasião para uma revolução científica. Todavia, há também certa soma de casualidade sobre quais fenômenos tornam-se o foco da investigação científica com base no paradigma que estrutura uma área de pesquisa em um determinado momento.

\subsection{A GiÊNGIA APLIGADA E o PLURALISMO METODOLÓGIGo}

$M_{2}$ serve como um modelo para racionalmente $\operatorname{aceitar}_{2} T_{1}$ (desenvolvida sob $E_{1}$ ) mais do que $T_{2}$ (desenvolvida sob $E_{2}$ ), onde $E_{1}$ e $E_{2}$ são estratégias incompatíveis que oferecem explanações e predições conflitantes pertencendo a domínios comparáveis de fenômenos do mundo da experiência vivida. Aceitar $T_{1}$, baseado sobre $M_{2}$, também implica, ao mesmo tempo, descartar $E_{2}$ como uma estratégia para moldar a pesquisa em curso envolvendo esses fenômenos. Kuhn o interpreta também como exigência da adoção de $E_{1}$ para moldar a pesquisa em andamento. Obviamente, pode-se esperar que a adoção de $E_{1}$ oriente pesquisas fecundas, mas isso não implica que $E_{1}$ seja a única estratégia que possa ser adotada para realizar esse fim. De fato, contrário a Kuhn, E2 pode ser descartada sem ser sucedida exclusivamente por $E_{1}$ (cf. Lacey, 2010, cap. 2). Adotar uma estratégia é inseparável da identificação dos tipos de possibilidades que podem ser manifestadas nas teorias desenvolvidas a partir dela; e descartar $E_{2}$, de acordo com $M_{2}$, permite ainda outra estratégia, $E 3$, bem como $E_{1}$, enquanto uma estratégia viável. E3 é viável se ela molda a investigação de um conjunto diferente de possibilidades mais do que $E_{1}$ (por exemplo, das possibilidades de agroecossistemas mais do que aqueles identificados na pesquisa biotecnológica), e se é fecunda, ou se se torna fe- 
cunda, caso a pesquisa conduzida a partir dela fosse sustentada por condições materiais e sociais apropriadas, onde "fecundo" (ver §1) refere-se ao sucesso em gerar conhecimento científico, conduzindo ou não esse conhecimento a aplicações bem-sucedidas e valiosas.

Se tanto $E$ r quanto $E 3$ são, até certo ponto, fecundas, não há garantia de que, eventualmente, seja possível fazer uma escolha entre ambas mediante o uso de M2. Além disso, a fecundidade de Eı não impede que a adoção de E3 possa levar ao entendimento considerado mais significativo (para algumas perspectivas de valor), isto é, mais aplicável a objetos valorizados e em atividades sociais valorizadas. Isso não é simplesmente uma possibilidade lógica abstrata. A ciência aplicada não é apenas um resultado da condução bem-sucedida da pesquisa no interior da ciência normal sem impacto sobre quais estratégias são adotadas na pesquisa. Os fenômenos e as possibilidades investigados na pesquisa científica não somente surgem no curso do direcionamento da ciência normal e por casualidade, mas também são frequentemente escolhidos por causa de seu interesse para aqueles que defendem perspectivas particulares de valor. E os fenômenos e as possibilidades interessantes para uma perspectiva de valor, que podem ser investigados sob El , podem não incluir aqueles que são interessantes para outra perspectiva de valor que requer a adoção de E3 para sua investigação. Ademais, certos fenômenos e possibilidades que são importantes no contexto de aplicação - por exemplo, aqueles ligados aos riscos, onde emergem questões ligadas à aceitação ${ }_{4}$ (ver \$2.2) demandam o uso de uma variedade de estratégias complementares (ver §1.2) a fim de serem adequadamente investigados.

Não obstante, Er e E3 podem competir de tal modo que a condução da pesquisa sob El é praticamente incompatível com condução sob E3 nos mesmos contextos sociais e ao mesmo tempo. A aplicação em projetos práticos amplia os caminhos suplementares àqueles indicados em §2 e \$2.1, nos quais as estratégias podem competir.

Em primeiro lugar, as teorias produzidas sob estratégias diferentes podem abarcar as possibilidades dos mesmos objetos - no caso das sementes, por exemplo, aquelas da agroecologia e aquelas introduzidas pela biotecnologia -, que não podem ser conjuntamente efetivadas nos mesmos espaços sociais, ou talvez (em alguma extensão significativa) em nosso mundo social compartilhado. Na aplicação, elas podem informar práticas humanas e, assim, moldar o mundo da experiência vivida, de modos fundamentalmente diferentes que servem a perspectivas de valor incompatíveis (cf. Lacey, 2006; 2010, parte 2). Dessa forma, existe competição sobre qual é a estratégia de conhecimento a ser aplicada. Por seu turno, uma vez que a pesquisa é dependente da disponibilidade de condições materiais e sociais relevantes, haverá também competição pelos recursos e condições necessários à pesquisa submetida àquelas estratégias. 
O desfecho dessa competição é fortemente influenciado por valores e forças sociais com interesse nas aplicações. A competição social tende a colocar impedimentos práticos no modo como certas estratégias são desenvolvidas, ou levar à consequência de que não se considerem os concorrentes de estratégias predominantes.

Em segundo lugar, existem suposições que refletem os compromissos de valor fundamentais das forças e instituições sociais contemporâneas (mais do que os resultados da investigação empírica), e que se tornaram profundamente entranhados no "senso comum" de nosso tempo, servindo, por exemplo, tanto para legitimar o papel expandido da biotecnologia na agricultura, quanto para apoiar a adoção de estratégias biotecnológicas mais do que agroecológicas na pesquisa (cf. Lacey, 2006; 2010, parte 2). Entre elas, incluem-se as pressuposições do valor do progresso tecnológico (cf. Lacey, 2008c), tais como "a inevitabilidade da globalização econômica" (cf. Lacey, 2006, cap. 6), e versões mais específicas dessas pressuposições, como "alimentar a população do mundo em rápida expansão exige o desenvolvimento e a implementação da agricultura informada pela biotecnologia". Suposições desse tipo tornam-se pressuposições de perspectivas de valor que têm relações de reforço mútuo com as estratégias adotadas na pesquisa (ver §1.2).

Esses tipos de competição mostram que os valores, que são bem servidos pela aplicação do conhecimento científico, podem repercutir, e influenciar, na escolha da estratégia a ser adotada na pesquisa. É importante manter separados os momentos (lógicos) da adoção da estratégia, quando os valores sociais e culturais têm papel legítimo, ${ }^{8}$ dos momentos da aceitação de teorias (os primeiros três sentidos), que repousa idealmente somente sobre os dados e os valores cognitivos. Isso permite que as teorias, desenvolvidas sob estratégias que competem segundo os modos já descritos, possam condensar classes diferentes de possibilidades das mesmas coisas, de modo que a competição estratégica não precisa sempre produzir competição teórica.

\section{A escollha da Adoção de uma estratéGia}

Quando se adota uma estratégia é (racionalmente) apropriado considerar tanto a sua fecundidade quanto a sua significação (valor social). Para Kuhn, somente a fecundidade é apropriada. Como discutido na $\S 2.3$, ele mantém que a pesquisa (em um dado cam-

8 Embora uma estratégia possa ser adotada nas pesquisas práticas em virtude de compromissos particulares de valor, a longo prazo, ela está sujeita a limitações empíricas, pois sua adoção está continuamente sujeita a testes de fecundidade. (É por isso que Kuhn confere importância metodológica à multiplicação de “anomalias" no interior do paradigma a ser descartado.) 
po) é normalmente conduzida sob uma estratégia única, adotada no desenlace das escolhas teóricas feitas de acordo com M2, com a consequência de que uma estratégia não fecunda seja descartada, deixando em seu lugar uma estratégia fecunda que é adotada até sua fecundidade ser exaurida.

É verdade que, de fato, a fecundidade basta para tornar racional a adoção de estratégias AD mais do que a de estratégias aristotélicas, mas não necessariamente mais do que quaisquer outras estratégias (cf. Lacey, 1999, cap. 7; 2010, cap. 2). Afecundidade manifesta e contínua de estratégias AD é compatível com algumas estratégias não-AD também fecundas. No início da revolução científica moderna, à luz dos valores emergentes da modernidade, as estratégias AD foram amplamente consideradas significativas (de grande valor social), assim como elas são hoje, talvez mais do que nunca. No século xvir, contudo, exceto para Bacon, com sua ênfase na "utilidade", a fecundidade parece ter sido considerada como suficiente para escolher entre as estratégias que foram acolhidas, e a significância foi considerada uma consequência feliz, mas acidental, da fecundidade das estratégias AD. Historicamente, uma variedade de estratégias tem sido empregada. Algumas (por exemplo, o mecanicismo cartesiano) têm sido completamente descartadas e, no interior da abordagem descontextualizada, a adoção de estratégias posteriores (por exemplo, a mecânica quântica) na pesquisa em curso, mais do que de estratégias anteriores (por exemplo, a newtoniana), é plausivelmente explicada em termos de M2.

Entretanto, a tendência da ciência em voga de não acolher seriamente as estratégias não AD, que são demonstrável ou potencialmente fecundas, não pode ser explicada desse modo. Ao invés disso, as razões para que não sejam levadas em consideração estão (implicitamente) vinculadas ao significado. Os produtos teóricos da pesquisa conduzida sob as estratégias AD foram aplicados de forma bem-sucedida nos projetos das principais forças sociais, e aplicam-se aos objetos tecnológicos que vieram a figurar tão centralmente em nossas vidas. Estes, e não os resultados da pesquisa conduzida sob estratégias agroecológicas, são de grande valor social para as mais poderosas perspectivas contemporâneas de valor, as quais incorporam os valores do progresso tecnológico e os valores do capital e do mercado (cf. Lacey, 2008c; 2010, p. 137-9). Na modernidade, então, é a combinação de fecundidade e de significação (para as perspectivas de valor dominantes) que direciona a adoção das estratégias AD, virtualmente, de maneira exclusiva (cf. Lacey, 1999, cap. 6, 7). Todavia, enquanto for mantido o pouco espaço disponível para o desenvolvimento de estratégias não AD nas instituições científicas, o papel da significação permanecerá escondido, e a questão da escolha entre $E_{1}$ e $E 3$ - entre o emprego exclusivo de estratégias AD e o de estratégias não AD em algumas áreas da pesquisa - será vista como puramente lógica. 
Os valores do progresso tecnológico e os valores associados à modernidade não são universalmente defendidos. Algumas pessoas os desafiam em virtude da devastação social e ecológica, que se entende ter sido difundida pela modernização em seu rasto (cf. Lacey, 2006, cap. 6; 2008b); outros o fazem porque aqueles valores contribuem para minar os valores "tradicionais", ou outros valores altamente estimados, e dimensões importantes do bem-estar humano que poderiam fornecer a base para formas alternativas de "desenvolvimento" (cf. Lacey, 1999, cap. 8; 2006, cap. 6; 2008c; Feyerabend, 1999, parte 2, cap. 9). Aqueles que questionam os valores do progresso tecnológico não questionam (ou não deveriam questionar) a fecundidade da pesquisa conduzida sob as estratégias AD. Ao contrário, eles questionam o significado (valor social) de muito do entendimento ganho à luz das estratégias AD, embora certamente não de todo. As estratégias não $\mathrm{AD}$ são complementares às estratégias $\mathrm{AD}$, e a pesquisa desenvolvida a partir delas pode aproveitar livremente do conhecimento positivo obtido com base nas estratégias AD. A adoção de estratégias não AD não é uma alternativa global à adoção de estratégias AD, mas uma resposta à inadequação das estratégias AD para conduzir pesquisas cuja meta é entender certos tipos de fenômenos (por exemplo, as possibilidades de agroecossistemas sustentáveis). 9 Esta é uma boa razão para procurarem estratégias alternativas capazes de gerar teorias aceitáveis e que são mais significativas à luz de seus valores, teorias que poderiam ser aplicáveis em suas formas de vida preferidas e aos fenômenos e possibilidades importantes para eles. O sucesso dessa busca não é garantido, mas o seu fracasso também não o é. Podem existir duas estratégias fecundas que permitam a identificação das possibilidades dos mesmos objetos, mas diferentes classes delas: por exemplo, suas possibilidades como relevantes para o controle tecnológico, e aquelas conectadas com a promoção da manifestação de valores sociais concorrentes, aos quais as implementações tecnológicas são consideradas como subordinadas (cf. Lacey, 2006, cap. 2; 2008d). Se existem ou não tais estratégias fecundas, isso só pode ser conhecido após a pesquisa adequada ter sido desenvolvida a partir das mesmas.

Muitos objetos, incluindo os fenômenos experimentais e tecnológicos, cujas possibilidades descontextualizadas são bem identificadas pelas estratégias AD, são também objetos de valor social. Frequentemente, as possibilidades descontextualizadas não podem ser realizadas (no contexto histórico) sem também realizar possibilidades

9 “(...) profissionais que lidam com as partes ecológicas, sociais e médicas de ajuda ao desenvolvimento vêm percebendo agora que a imposição de procedimentos "racionais" ou "científicos", embora ocasionalmente benéficos (eliminação de alguns parasitas e doenças infecciosas), podem levar a sérios problemas materiais e espirituais. Eles não abandonam o que aprenderam em suas universidades; todavia, combinam esse conhecimento com crenças locais e costumes e, desse modo, estabelecem um nexo muito necessário com os problemas da vida que nos cercam em toda parte" (Feyerabend, 1993, p. xiv). 
sociais particulares e minar outras. Nesses casos, ambos os tipos de possibilidades podem (em princípio) ser investigadas sistemática e empiricamente. Por exemplo, as possibilidades das sementes transgênicas, identificadas pela pesquisa biotecnológica, não podem ser realizadas (sob as condições correntes) sem promover o processo social de transformar as sementes em mercadorias, e isso muda não somente o caráter da agricultura, como também tem profundas implicações ecológicas e sociais (cf. Lacey, 2006, cap. 3; 2010, parte 2; 2011c). A identificação de certos tipos de possibilidades de sementes transgênicas tem sido estabelecida de acordo com a imparcialidade, assim como a transformação mais completa de sementes em mercadorias. Ambas são afirmações propriamente aceitas, estabelecidas à luz dos dados disponíveis e dos valores cognitivos. Elas não podem ser propriamente desafiadas baseando-se nos valores sociais que alguém defende. A mercantilização das sementes, no entanto, não representa um valor universal e, assim, ceteris paribus, as práticas de pesquisa que aumentam nossa compreensão das possibilidades dos transgênicos não serão universalmente consideradas de elevado valor social. Considere-se os dois tipos de possibilidades sobre a produção de colheita (ver $\S 1.2$ ). O primeiro diz respeito a sua serventia ao bem-estar local e a sustentabilidade do meioambiente; o segundo refere-se à maximização sob condições amplamente replicáveis. Aqueles que adotam exclusivamente as estratégias $\mathrm{AD}$ (incluindo aquelas da biotecnologia) são efetivamente capazes de abordar questões sobre o segundo tipo, mas questões sobre o primeiro tipo não podem ser abordadas, se alguém as dissocia dos contextos sociais e ecológicos. As questões do primeiro tipo, contudo, terão maior importância para aqueles cujos valores estão em conflito com os valores do progresso tecnológico e os valores socioeconômicos (por exemplo, o crescimento econômico) que são usualmente incorporados nas poderosas instituições modernas (cf. Lacey, 2008c). Assim, uma vez que essas questões estão abertas à investigação empírica sob estratégias agroecológicas, estas estratégias corretamente ganharão precedência. A racionalidade não exige que eles esperem até que a fecundidade dos tipos concorrentes de estratégias AD tenha sido exaurida.

A demonstrada fecundidade de longo alcance e continuamente em expansão das estratégias AD não são razões suficientes para adotá-las exclusivamente. É razoável para aqueles que desafiam os valores do progresso científico e do capital e do mercado adotar estratégias não AD em seus projetos de pesquisa em virtude da promoção dos valores que eles abraçam, embora, hoje, a extensão da fecundidade potencial da adoção de tais estratégias ainda tenha que ser severamente testada. Se for para atingir as condições sociais e materiais necessárias para progredir, então todas as estratégias conflitantes podem ser fecundas, elas podem encapsular diferentes classes de possibilidades dos mesmo objetos (por exemplo, as sementes). 
3.1 UM MODELO PARA DEGIDIR QUAL ESTRATÉGIA ADOTAR

À luz dessas considerações, afastando-me bastante de Kuhn, eu proponho um terceiro modelo, M3, um modelo para decidir qual estratégia adotar.

M3: Adotar somente uma estratégia (potencialmente) fecunda; porém, se ambas as estratégias concorrentes $E_{1}$ e $E_{2}$ são (potencialmente) fecundas, adotar aquela que possa produzir o entendimento do significado dos valores culturais, éticos e sociais que alguém defende racionalmente.

M3 é proposto como um modelo a ser seguido por um pesquisador individual (ou grupo de investigadores). M3, no entanto, é compatível com o pluralismo estratégico que eu tenho defendido. Ele não envolve a rejeição de uma das duas estratégias fecundas concorrentes. Pesquisadores que defendem diferentes perspectivas de valor podem apelar para $M 3$ a fim de sustentar a adoção de estratégias diferentes. Assim, suas diferenças são localizadas no nível dos valores sociais, éticos e culturais, e não em juízos de valor cognitivos. M3 não é um modelo para a escolha de teoria. Seu uso não ampara os juízos de que a "melhor" teoria a encaixar-se nas restrições da estratégia favorecida seja assim aceitável ${ }_{2}$, ou de que as teorias desenvolvidas sob estratégias concorrentes deveriam ser rejeitadas (seja rejeitada ${ }_{1}$, seja rejeitada ${ }_{2}$ ). Ter boas razões para adotar $E_{1}$ não implica que não existam teorias, desenvolvidas sob E2, que sejam (ou devem ser) aceitas 1 para certos domínios de fenômenos. Quando isso é ignorado, como é possível que seja o caso em que haja uma perspectiva de valor compartilhada entre membros da comunidade científica, os juízos que não estão de acordo com a imparcialidade são os mais prováveis de serem feitos, pois, se somente uma estratégia é seguida onde existem alternativas potencialmente fecundas, então será fácil inferir (inadvertidamente ou de outro modo qualquer) que a partir de "não existem possibilidades de um certo tipo que possam ser encapsulas por $E_{1}$ (por exemplo, as estratégias AD)" chega-se a "não existem de fato possibilidades desse tipo" - embora a pesquisa conduzida sob $E_{1}$, por si mesma, não possa sustentar essa conclusão. Esse tipo impróprio de inferência tende a ser feito (implicitamente) pelos proponentes do uso de transgênicos quando afirmam "não há riscos" e "não há alternativas" (cf. Lacey, 2006, cap.4; 2010, cap. 4; 2011c). O consenso virtual na comunidade científica sobre questões como essa não deveria ser confundido com sua aceitação ${ }_{1}$ de acordo com a imparcialidade, pois tal consenso não deriva necessariamente da evidência empírica disponível, mas de uma perspectiva de valor compartilhada.

A fim de assegurar que $M 3$ não seja usado em modos que subjazem aos juízos que estão em desacordo com a imparcialidade, o pluralismo estratégico precisa ser segui- 
do no interior da comunidade científica (localizada no amplo corpo mundial das instituições e organizações científicas), acompanhado por supervisão apropriada para garantir que a pesquisa conduzida sob uma adequada pluralidade seja sustentada (cf. Lacey, 2011b; no prelo). Segue-se que M3 é um modelo apropriado para a escolha estratégica de cientistas individuais somente se for empregado no interior de uma comunidade científica comprometida com um princípio, tal como:

$P$ : Deve-se fornecer apoio à pesquisa desenvolvida a partir de um conjunto apropriado de estratégias concebidas com o intuito de assegurar que o fenômeno possa ser adequadamente investigado através de um modo que seja sensível ao ideal da imparcialidade.

Para estabelecer um equilíbrio adequado entre a autonomia científica e a democracia, é necessário elaborar o que conta como uma pluralidade apropriada de estratégias e qual é a supervisão apropriada (cf. Lacey, 2008b, 2011b, no prelo; Oliveira, 2011). M3, complementada por $P$, tem afinidades com vários temas de Paul Feyerabend, a saber, a importância metodológica da proliferação de teorias (cf. Feyerabend, 1981), a multiplicidade de tradições científicas, muitas das quais envolvem interação e continuidade com formas tradicionais de conhecimento, a utilidade de tal proliferação e multiplicidade para o ganho de acesso a possibilidades que são importantes às razões "humanitária" e "democrática”, mas que, de outro modo, são inacessíveis (cf. Feyerabend, 1993), as teorias científicas são avaliadas apropriadamente por seu valor ético [significação] ou seu lugar em um modo de vida (cf. Feyerabend, 1999), e a dominação de uma única ciência (cujo desenvolvimento está submetido às estratégias $\mathrm{AD}$ ) ameaça o bem-estar humano (cf. Feyerabend, 1993, 1999).

A fim de funcionar bem, o pluralismo metodológico normalmente precisa ser praticado em uma comunidade científica na qual exista uma diversidade de valores mantidos pelos pesquisadores, os quais adotam estratégias para suas próprias atividades de pesquisa de acordo com M3, e a qual tolera (ou melhor, encoraja ativamente) a pesquisa conduzida sob estratégias adversárias que estão atreladas a valores concorrentes (ver $§ 3.3)$.

\subsection{Os OBSTÁGULOS PARA USAR O MODELO APROPRIADAMENTE}

A combinação de $M 3$ e $P$ enfrenta sérios obstáculos na prática. Quando estratégias competem a respeito da aplicação em projetos práticos, a concorrência que se segue por recursos pode levar a ignorar completamente a importância de $P$, e deixar uma das estratégias menos desenvolvida de forma significativa, a ponto de seu potencial de 
fecundidade não poder ser prontamente discernível. Logo, uma estratégia pode ser seguida como se ela não tivesse competidora legítima. A estratégia favorecida por forças e instituições sociais dominantes esconde, assim, o papel que os valores desempenham em sustentar a sua adoção (ver §2.4), e não submete à investigação as pressuposições das perspectivas de valor das forças dominantes. Por exemplo, manter os valores do progresso tecnológico - com respeito ao valor das inovações tecnocientíficas introduzidas em prol do crescimento econômico - pressupõe alegações tais como: "a inovação tecnocientífica proporciona benefícios que contribuem para o bem-estar dos seres humanos em geral", "há soluções tecnocientíficas para a maioria dos problemas humanos, incluindo aqueles ocasionados pelas próprias inovações tecnocientíficas", "hoje, não existem propostas de alternativas sérias à busca de crescimento econômico baseada na inovação tecnocientífica”. Essas pressuposições estão abertas à investigação empírica, mas não sob as estratégias AD, embora as estratégias não AD tendam a não ser seriamente acolhidas onde os valores do progresso tecnológico são amplamente abraçados (cf. Lacey, 2008c; 2009). A conclusão pode ser a de que propostas desenvolvidas sob estratégias que competem com as estratégias dominantes são interpretadas como sendo virtualmente ininteligíveis (ver as dificuldades de comunicação que Kuhn discerne quando há conflito entre paradigmas, §2.1.) Basta pensar naquelas formas de agroecologia que mantêm continuidade explícita com as práticas agrícolas tradicionais em algumas das regiões pobres do mundo. Por um lado, se a pesquisa agroecológica obtivesse as condições materiais e sociais necessárias para explorar plena e sistematicamente as possibilidades de produção da safra servindo ao bem-estar local, e se fosse bem-sucedida, isso ameaçaria a crescente dominação do agronegócio e desafiaria algumas das pressuposições da "globalização" (cf. Lacey, 2006, cap. 6), sendo ambas bem servidas pelos desenvolvimentos científicos (por exemplo, na biotecnologia) feitos sob estratégias AD. Por outro lado, as categorias empregadas sob as estratégias AD ganharam tanto peso nas capacidades imaginativas e conceituais contemporâneas que a ideia de que possa existir alternativas sérias à pesquisa submetida a essas estratégias, nas quais as teorias legitimamente aceitas devem ser consolidadas, não tende a ser nem mesmo considerada (cf. Lacey, 1999, p. 126-3o; 2009). Portanto, com efeito, as prescrições das estratégias AD passam a ser tratadas como se fossem valores cognitivos (cf. Lacey, 2010, cap. 11, nota 11).

A tendência de confundir as prescrições estratégicas dominantes com os valores cognitivos explica, em parte, a falta de reconhecimento do papel que $M 3$, complementado por $P$, deveria desempenhar. Essa confusão pode ser reforçada pelo fato de que raramente uma estratégia é adotada como resultado de deliberação explícita. Geralmente (em primeira instância) um investigador engaja-se em atividades de pesquisa subordinadas às estratégias estabelecidas de modo que um principiante, por exemplo, 
aprende ao mesmo tempo como seguir as prescrições estratégicas e como avaliar os graus de manifestação dos valores cognitivos. Logo, devemos ser cautelosos com as defesas das estratégias dominantes do tipo: "esta é única forma de se jogar por aqui". Pode ser o único jogo jogado nas "arenas" da atual ciência institucionalizada, porque (com ou sem consciência) os concorrentes foram suprimidos, não foram reconhecidos, não atraíram adeptos ou foram negados recursos para o seu desenvolvimento. No entanto, isso não implica que a pesquisa, conduzida sob diferentes estratégias, não possa ser jogada em ‘arenas' diferentes, talvez nas “arenas” de uma ciência apropriadamente reinstitucionalizada (cf. Lacey, 2008b; no prelo).

O emprego explícito de $M 3$ em argumentos para justificar a adoção de uma estratégia provavelmente leva ao reconhecimento de que, submetendo-se à referida estratégia, várias classes de possibilidades ficarão inexploradas, e que suposições sobre algumas das possibilidades inexploradas estão entre aquelas que apoiam tanto o valor da adoção da estratégia, quanto a legitimidade de aplicar-se seus produtos (ver nota ๆ). Por exemplo, a aplicação de tecnologia transgênica - e, de fato, a adoção das estratégias de pesquisa biotecnológica - é frequentemente legitimada a partir do apelo à suposição: "é necessário alimentar a população mundial que está em rápido crescimento"; suposição que, por sua vez, assume que outras abordagens da agricultura, incluindo aquelas da agroecologia, não conseguem produzir a quantidade de alimento demandado (cf. Lacey, 2006, cap. 5; 2010, cap. 4, 7-9; 2008b). Essas suposições não são resultados de pesquisa conduzida sob estratégias AD, e não podem ser. Elas somente poderiam ser estabelecidas mediante pesquisa que envolvesse o desenvolvimento extensivo de estratégias tais como a da agroecologia. Não é suficiente mostrar que a tecnologia transgênica proporciona uma gama de benefícios, pois isso é compatível com a agroecologia ser um competidor comparável ou superior e também com os efeitos colaterais prejudiciais da aplicação da tecnologia transgênica superando seus benefícios.

\subsection{A neUtralidade E o PLURALismo metodolóGigo}

Minha defesa do pluralismo metodológico envolve as afirmações de que (1) a pesquisa conduzida a partir de estratégias não redutíveis às estratégias $\mathrm{AD}$ pode ser fecunda, e de que (2) alguns fenômenos, ou aspectos deles, somente podem ser entendidos de forma adequada se seguirem a pesquisa conduzida a partir de estratégias não AD. A importância dessas afirmações está ligada ao ideal de neutralidade, que, assim como a imparcialidade, foi a base da autocompreensão da tradição científica moderna (cf. Lacey, 2008a; 2010, cap. 1). O conhecimento científico é um dos "bens" comuns da humanidade; em princípio, o conhecimento científico pode ser usado (na aplicação), mais ou menos de forma equitativa, para informar projetos moldados por interesses 
que incorporam quaisquer valores éticos/sociais/culturais viáveis (cf. Lacey, 1999, cap. 3, 10; 2006, Introdução; no prelo). Eu interpreto isso como significando, não que cada item de conhecimento científico estabelecido possa ser usado, mas sim que do estoque de conhecimento estabelecido, para qualquer interesse particular, alguns itens podem ser escolhidos para informar seus projetos ou, de modo mais plausível, que o constante acúmulo de conhecimento científico permite, de maneira crescente, que mais e mais interesses sejam atendidos através da aplicação do conhecimento científico.

O uso virtualmente exclusivo de estratégias AD nas práticas científicas não pode produzir resultados que estejam de acordo com a neutralidade, pois isso favorece especialmente os valores do progresso tecnológico e os interesses do capital e do mercado (ver §3). Assim, a fim de aproximarem-se mais do ideal de neutralidade, as instituições científicas teriam que ser reconstituídas, de modo a criar uma comunidade de investigadores comprometida com o princípio $P$ (ver $§ 3.1$ ), ou seja, uma comunidade que mantenha de pé a legitimidade do emprego de uma pluralidade de estratégias, e que proporcione as condições para o desenvolvimento de um conjunto de estratégias (incluindo, por exemplo, as agroecológicas, bem como as biotecnológicas). Em tal comunidade, disputas em torno de estratégias concorrentes seriam partes normais da atividade científica, e as aplicações seriam permitidas e esperar-se-ia que elas fossem bem informadas pelo conhecimento obtido à luz de uma pluralidade de estratégias. Nessa comunidade, seriam desenvolvidos tantos espaços sociais quanto fossem possíveis para a exploração das estratégias alternativas e, assim, para o encorajamento dos investigadores a moderarem os compromissos que têm com os valores ligados às estratégias que adotam, com humildade e tolerância em relação a outras abordagens (tanto científicas quanto socioeconômicas). Não insinuo que esse contexto possa ser efetivado simplesmente mediante escolhas e juízos feitos no interior da comunidade científica sem maiores mudanças na ordenação socioeconômica (cf. Lacey, 2008b; no prelo).

Isso não é endossar o relativismo, mas apenas reconhecer que diferentes classes de possibilidades estão identificadas sob estratégias concorrentes, e que elas podem não estar aptas a serem realizadas conjuntamente nos mesmos lugares e projetos. Ademais, o compromisso com $M 3$, complementado por $P$, não implica a negação de que a pesquisa conduzida sob estratégias AD seja capaz de expansão indefinida. Entretanto, é compatível com algumas possibilidades que não são redutíveis àquelas que são descontextualizadas (cf. Lacey, 2009). A expansão indefinida das possibilidades que podem ser reveladas pela pesquisa biotecnológica, por exemplo, não proporciona razão para a manutenção de que as possibilidades dos constituintes de agroecossistemas sustentáveis possam ser encapsuladas em estratégias biotecnológicas (cf. Lacey, 2006, cap. 2, 5; 2010, cap. $5^{-8)}$. 
Pluralismo metodológigo, incomensurabilidade e o status científico...

\section{O GONHECIMENTO TRADICIONAL}

O argumento em favor do pluralismo metodológico permite levar a sério que os valores derivados de diferentes culturas e incorporadas em formas de vida radicalmente diferentes apontam para a importância das questões abertas às respostas baseadas em evidências empíricas, mas deixadas de lado pela ciência moderna em voga, acerca dos objetos materiais (por exemplo, as sementes) que não estão dissociados de seu lugar na experiência humana e nas estruturas sociais. Em princípio, não há razão para negar que haja estratégias fecundas incompatíveis com as estratégias AD unicamente privilegiadas, e que competem com elas a respeito da aplicação em projetos práticos. Isso sugere o valor potencial de identificação de estratégias alternativas, as quais podem envolver ricos desenvolvimentos de estratégias empenhadas na obtenção de "conhecimento tradicional”. Além disso, a preocupação com a justiça social, informada pelos valores de várias culturas, pode levar à antecipação da significação potencial dos produtos que tais estratégias podem gerar. Por exemplo, elas podem identificar com sucesso possibilidades originais de produção de cultura agrícola, restaurando sistemas ecológicos devastados e o bem-estar local. O conhecimento indígena não precisa opor-se ao conhecimento científico, e somente a investigação caso-a-caso pode estabelecer se as suas credenciais cognitivas são adequadas ou deficientes para lidar com os objetos particulares da investigação. As práticas de conhecimento tradicional, desde que sujeitas à restrição empírica - não necessariamente restrições impostas pelos dados obtidos no laboratório, mas também pelo "teste da prática", pelo exercício do "saber-fazer" prático, e pelo "teste do tempo" -, podem ser razoavelmente incorporadas sob a categoria de "ciência".

Há um crescente número de publicações exibindo a riqueza, a variabilidade, a versatilidade, a sensibilidade às questões relativas à sustentabilidade, à solidez empírica (que não é solapada por estar em sintonia com os interesses e os valores de grupos culturais particulares), e à abertura ao desenvolvimento mediante a pesquisa empírica sobre o conhecimento tradicional e indígena (cf. Brush \& Stabinsky, 1996; Pimbert, 2009; Santos, 2004, parte 4; 2007). O modo como o termo "ciência" está sendo usado neste artigo, que admite o pluralismo metodológico, pode incorporar todas essas formas de conhecimento, enquanto conserva suas características específicas e não lhes impõe um molde no qual, supostamente, estaria encaixada toda a investigação científica. Essas formas de conhecimento tornam-se recursos indispensáveis para abordar - cientificamente - as possibilidades de práticas alternativas que não são dependentes de inovações tecnocientíficas. Os autores supracitados preferem falar dessas formas de conhecimento não como "científicas", mas como "outros conhecimentos", ou "co- 
nhecimentos descolonizados", terminologia que os autores pretendem que tenha conotações relativistas. Não é importante para o meu argumento a maneira como a palavra "ciência" é usada, e se essas outras formas de conhecimento são, ou não, chamadas "científicas". O que importa é que elas têm credenciais empíricas legítimas, que a posse dessas credenciais não depende do uso de metodologias AD, que elas as exibem de um modo em nada inferior àquele exibido pelas estratégias AD, e que estão abertas ao desenvolvimento contínuo em bases empírica e teórica.

Possuir credenciais cognitivas legítimas não implica que um item de conhecimento tradicional seja significante, pois a significação depende de que seja parte integrante das práticas de grupos que tenham adeptos reais, e capacidade de obter espaço para desenvolver projetos que possam contribuir para o desdobramento do mundo de um modo tal que incorpore seus valores tradicionais, seu modo de pensar sobre o mundo e suas aspirações culturais. Neste artigo, trato apenas da questão das credenciais cognitivas do conhecimento tradicional. Isso possui pouca importância, contudo, para além de como se integra às concepções tradicionais de vida e de mundo, que são centrais para a autoarticulação da cultura, e com o modo como (ao mesmo tempo) conforma os movimentos vitais para a transformação social. Aqui, eu apenas discuto que não há argumentos convincentes de que o conhecimento tradicional seja carente de credenciais cognitivas legítimas. Isso não é mais do que um prolegômeno ao engajamento ativo com as práticas do conhecimento tradicional viável, ao aprendizado que elas podem estar aptas a oferecer ao entendimento do mundo da experiência vivida hoje, e às possibilidades que podem abrir para corrigir os danos (por exemplo, aquecimento global) causados pela adoção hegemônica dos valores do progresso tecnocientífico.

A conotação de relativismo, mencionada acima, é desnecessária (e infundada). O que está sendo tratado aqui não é o conhecimento relativo às culturas particulares, mas abordagens de investigação que refletem adequadamente o caráter, os aspectos ou as possibilidades do objeto investigado (aspectos que podem ser considerados importantes, nos quais são mantidos valores culturalmente específicos), e possibilidades que podem ser realizadas em sua maior parte somente em condições fornecidas pela cultura. Isso não torna o conhecimento, enquanto distinto de sua significação, relativo a esses valores culturais (cf. Lacey, 2010, cap. 3).

A ciência, enquanto uma prática de obtenção de conhecimento que em um grau considerável pode ser institucionalizada separadamente de outras práticas sociais (incluindo aquelas em que o conhecimento científico é aplicado) e praticada principalmente por profissionais educados de forma técnica, tem sido cultivada predominantemente nas culturas ocidentais. Entretanto, a ciência, tal como caracterizada desde o início do artigo, não se limita a essas práticas e às atividades de profissionais formados 
tecnicamente. O conhecimento científico pode ser obtido em culturas nas quais não está incorporada a separação institucional entre as práticas de obtenção de conhecimento e as demais práticas sociais, o que conta como conhecimento científico não está precisamente separado de outras crenças amplamente compartilhadas em uma cultura. Mesmo o conhecimento científico moderno não está, em si mesmo, sempre nitidamente separado da crença de que prosseguir em uma pesquisa submetida à estratégias AD seja essencial para satisfazer as necessidades do mundo. Essa crença não é um item do conhecimento científico estabelecido, embora aqueles que questionam isso sejam frequentemente considerados contrários à ciência. A "ciência” não deveria identificar-se com "o que largamente se crê nas instituições científicas modernas". Talvez seja por sentirem que a "ciência" é geralmente entendida desse modo que os autores mencionados anteriormente se inclinem às interpretações relativistas. E certamente "conhecimento tradicional" não deveria ser identificado com "crenças" tradicionais; "conhecimento" é aquilo que exibe credenciais cognitivas adequadas. Eu não sei qual é a extensão dos conhecimentos tradicionais e indígena. Apesar de não duvidar de que alguns entusiastas fazem alegações exageradas a respeito de sua amplitude, prima facie de que a visão de mundo de uma cultura (cf. Lacey, 2011a) inclui um olhar de como "a natureza é benevolente" - um exemplo dado em Siegel, (2001), sem qualquer elaboração que a acompanharia nas articulações da própria cultura -, isso não é per se uma razão para descartar as credenciais científicas de declarações específicas associadas a ela, as quais estão abertas à avaliação empírica. Somente a inconsistência com uma teoria propriamente aceita sob estratégias AD (ou outra) fornece tal razão; e, certamente, não é suficiente que seja inconsistente com a metafísica materialista, a visão de que as possibilidades das coisas e dos fenômenos são esgotadas por suas possibilidades descontextualizadas (cf. Lacey, 2011a).

As categorias da metafísica materialista (continuamente refinadas à medida que são extrapoladas a partir dos desenvolvimentos científicos mais recentes) parecem dominar as imaginações dos intelectuais contemporâneos de mentalidade científica, como se devessem ser limitações impostas sobre nossas investigações. Não é clara a razão para que isso seja assim (cf. Lacey, 2009; 2011a). São poucos os que ainda aderem a argumentos a priori para sustentar a metafísica materialista. Além disso, a metafísica materialista não é um pressuposto da investigação empírica sistemática (uma vez que pode haver estratégias fecundas ligadas a pressupostos que são inconsistentes com ela); e, enquanto extrapolação dos resultados das investigações submetidas às estratégias AD, a metafísica materialista não pode fundamentar os privilégios dessas estratégias (cf. Lacey, 2011a). Meu palpite é que as bases para a adesão ao materialismo metafísico e para a adoção vitualmente unânime das estratégias AD são as mesmas, a saber, as relações de reforço mútuo com os valores do progresso tecnológico 
(cf. Lacey, 1999, p. 126-30; 2009; 2011a). A alusão à metafísica materialista tende a subjazer aos argumentos comuns contra a possibilidade do pluralismo metodológico. Harvey Siegel, por exemplo, constrói seu argumento contra a possibilidade da "ciência multicultural" a partir da alegação de que (toda) pesquisa científica tem um objeto comum, "o mundo natural", ou partes dele, ou objetos desse mundo "que têm propriedades independentes do contexto cultural no qual as pessoas os estudam, [na qual] tais propriedades são mais bem estudadas e entendidas (...) nos modos recomendados e exemplificados através de princípios e práticas metodológicos 'ocidentais' [isto é, subordinadas às estratégias AD]" (Siegel, 2001, p. 216).

Kuhn, certamente, discorda de Siegel. Para ele, os objetos investigados a partir de diferentes estratégias são amplamente heterogêneos, ocupantes de "mundos diferentes", os quais são parcialmente constituídos por e nas próprias atividades de pesquisa. E eu, não me distanciando muito de Kuhn, sugeri que os objetos de investigação conduzida sob as estratégias AD podem ser considerados enquanto possibilidades descontextualizadas das coisas. Em todas as culturas, algumas das possibilidades descontextualizadas são proeminentes (visto que nenhuma das possibilidades é realizada sem também realizar certas possibilidades descontextualizadas). Não obstante, aquelas possibilidades não esgotam as possibilidades das coisas na medida em que fazem contato com nossas vidas, embora talvez esgotem, em princípio, as possibilidades do controle tecnológico. O entendimento do "mundo natural", "do mundo no qual vivemos", não se reduz ao entendimento obtido mediante o emprego de estratégias AD. Além disso, as teorias desenvolvidas por diferentes estratégias podem competir em suas considerações sobre quais possibilidades são concebíveis no mundo da experiência vivida por meio dos objetos e em interação com os objetos encontrados no próprio mundo social. Se a ciência é uma investigação empírica sistemática que nos permite compreender "o mundo no qual vivemos" e que serve para instruir nossas atividades práticas, então há certa urgência em explorar concretamente o escopo potencial do pluralismo metodológico - incluindo as estratégias implantadas, explícita ou implicitamente, no desenvolvimento de formas de conhecimento tradicional - e nenhuma razão para antecipar que somente uma estratégia passará no teste de proficuidade. Decerto, dado que as estratégias ligadas a diferentes valores culturais irão concorrer com as estratégias AD a respeito da aplicação em projetos práticos, pode-se esperar que os principais obstáculos a tais explorações sejam mantidos (ver §2.4; Lacey, 2006, cap. 6).

A chave do meu argumento é que há estratégias concorrentes praticamente incompatíveis, e todas podem ser fecundas. Elas são as fontes da incomensurabilidade metodológica (ver §2.2). As estratégias fecundas rivais não precisam gerar teorias concorrentes. Suas respectivas teorias razoavelmente aceitas podem encapsular classes 
bem diferentes de possibilidades do mesmo fenômeno, cuja realização nas aplicações práticas pode servir a valores éticos e sociais distintos. Onde os valores do progresso tecnológico são profundamente arraigados, não surpreende que haja entraves ao desenvolvimento de estratégias teóricas e práticas que competem com as estratégias AD e até mesmo ao reconhecimento de sua inteligibilidade e, portanto, que as credenciais cognitivas do conhecimento indígena sejam rejeitadas sem muita atenção da audiência. Repito que não sei qual é o alcance dos conhecimentos indígenas e tradicionais. Isso, porém, carrega um registro inequívoco de fecundidade: o conhecimento tradicional informou as práticas de seleção que nos legaram as sementes indispensáveis para o cultivo de todas as culturas agrícolas de hoje, e sem a quais os transgênicos seriam impossíveis (cf. Lacey, 2010, cap. 6).ه

Traduzido do original em inglês por Leonardo Rogério Miguel, Antonio Augusto Passos Videira $\&$ André Luis de Oliveira Mendonça.

Agradecimentos. Este artigo expande e inclui revisões de partes de Lacey (2001) e Lacey (2005, cap. 4). Agradeço os tradutores pelo trabalho muito bem feito, e a Marcos Barbosa de Oliveira e Isabel Loureiro pelos comentários úteis sobre a $\$ 4$.

Hugh LAGEY

Professor Emérito, Swarthmore College, EUA. Pesquisador Colaborador do Projeto Temático 2011/51614-3,

"Gênese e significado da tecnociência", Fundação de Amparo à Pesquisa do Estado de São Paulo; Pesquisador do Instituto de Estudos Avançados, Universidade de São Paulo, Brasil. hlaceyı@swarthmore.edu 


\begin{abstract}
Cultural values may constructively have impact on scientific practices, and lead to legitimate culturebased variations in approaches to them. It follows that traditional or indigenous knowledge need not stand opposed to scientific knowledge, and only investigation on a case-by-case basis can establish whether or not the cognitive credentials of particular traditional knowledge claims are adequate or deficient. Building on an analysis of how different methodological strategies may both compete and complement one another, I argue that what is defensible about Thomas Kuhn's notion of incommensurability, and the possibility of the sound scientific status of traditional knowledge, have the same source.
\end{abstract}

KEYwords • Methodological pluralism. Incommensurability. Kuhn. Traditional knowledge. Impartiality. Neutrality. Methodological strategies.

\title{
REFERÊNGIAS BIBLIOGRÁFICAS
}

Altieni, M. A. Agroecology: the scientific basis of alternative agricultures. Boulder: Westview, 1987 .

Brush, S. B. \& StaBinsky, S. (Ed.). Valuing local knowledge: indigenous people and intellectual property rights. Washington: Island Press, 1996.

Cruz, E. R. (Ed.). Teologia e ciências naturais: teologia da criação, ciências naturais e tecnologia em diálogo. São Paulo: Editora Paulinas, 2011.

Dupas, G. (Ed.). Meio-ambiente e crescimento econômico: tensões estruturais. São Paulo: Editora UNESP, 2008.

EмвRAPA - Grupo de trabalho em agroecologia. Marco referencial em agroecologia. Brasília: Embrapa Informacão Tecnológica, 2006. Disponível em: 〈http://www.4shared.com/office/Uo-HDUKF/ Agroecologia_Marco_referenci. html>.Acesso em: 10 mar. 2012.

Feyerabend, P. K. Problems of empiricism. Cambridge: Cambridge University Press, 1981. Against method. 3a ed. London: Verso, 1993.

. Conquest of abundance: a tale of abstraction versus the richness of being. Chicago: Chicago University Press, 1999.

Hoyningen-Huene, P. Reconstructing scientific revolutions: Thomas S. Kuhn's philosophy of science. Chicago: University of Chicago Press, 1993.

Hoyningen-Huene, P. \& SAnkey, H. (Ed.). Incommensurability and related matters. Dordrecht: Kluwer, 2001.

KoIDE, K. I. O papel dos valores cognitivos e não-cognitivos na atividade científica: o modelo reticulado de Larry Laudan e as estratégias de pesquisa de Hugh Lacey. São Paulo, 2011. Dissertação (Mestrado em Filosofia). Faculdade de Filosofia, Letras e Ciências Humanas, Universidade de São Paulo.

Kunn, T. S. The structure of scientific revolutions. 2 ed. Chicago: University of Chicago Press, 1970. The road since the structure. Chicago: University of Chicago Press, 2000.

LACEY, H. Is science value free? Values and scientific understanding. London: Routledge, 1999. . Incommensurability and "multicultural science". In: Hoyningen-Huene, P. \& Sankey, H. (Ed.). Incommensurability and related matters. Dordrecht: Kluwer, 2001. p. 225-39.

. Values and objectivity in science; current controversy about transgenic crops. Lanham, MD: Lexington Books, 2005.

. A controvérsia sobre os transgênicos: questões científicas e éticas. São Paulo: Editora Ideias e Letras, 2006.

.Valores e atividade científica ı. São Paulo: Associação Filosófica Scientiae Studia/Editora 34, 2008a. 
Pluralismo metodológigo, ingomensurabilidade e o status científico...

LAGey, H. Ciência, respeito à natureza e bem-estar humano. Scientiae Studia, 6, 3, p. 297-327, 2008b. Crescimento econômico, meio-ambiente e sustentabilidade social: a responsabilidade dos cientistas e a questão dos transgênicos. In: Dupas, G. (Ed.). Meio-ambiente e crescimento econômico: tensões estruturais. São Paulo: Editora UNESP, 2008c. p. 91-13o.

. Aspectos cognitivos e sociais das práticas científicas. Scientiae Studia, 6, 1, p. 83-96, 2008d.

. O lugar da ciência no mundo dos valores e da experiência humana. Scientiae Studia, 7, 4, p. 681701,2009 .

. Valores e atividade científica 2. São Paulo: Associação Filosófica Scientiae Studia/Editora 34, 2010. . A interação da atividade científica, visões de mundo e perspectivas de valores. In: CRuz, E. R. (Ed.). Teologia e ciências naturais: teologia da criação, ciências naturais e tecnologia em diálogo. São Paulo: Editora Paulinas, 2011a. p. 127-47.

. A imparcialidade e as responsabilidades dos cientistas. Scientiae Studia, 9, 3, p. 487-500, 2011 b.

. Prefácio. In: TAIT, M. Tecnociência e cientistas: cientificismo e controvérsias na política de biossegurança brasileira. São Paulo: Editora Annablume, 2011c. p. 13-29.

Reflections on science and technoscience. Scientiae Studia, 10, Special issue, p. 103-28, 2012.

Las diversas culturas y la práctica de la ciencia. In: Molina, F. T. \& Giuliano, G. (Ed.). Culturas científicas y alternativas tecnológicas. Buenos Aires: Mincyt (Ministerio de Ciencia, Tecnología e Innovación Productiva). No prelo.

Molina, F. T. \& Giuliano, G. (Ed.). Culturas científicas y alternativas tecnológicas. Buenos Aires: Mincyt (Ministerio de Ciencia, Tecnología e Innovación Productiva). No prelo.

Oliveira, M. B. de. Formas de autonomia da ciência. Scientiae Studia, 9, 3, p. 527-61, 2011.

Pimbert, M. Towards food sovereignty: reclaiming autonomous food systems. London: International Institute for Environment and Development, 2009. Disponível em: <http://www.iied.org/pubs/display.php?o= Go24, $3 \& \mathrm{n}=1 \& \mathrm{l}=3 \& \mathrm{k}=$ Towards $\% 2$ oFood $\%$ 20Sovereignty $\% 20$ Reclaiming $\%$ 2oautonomous $\%$ 2ofood \%20systems>. Acesso em: 10 mar. 2012.

Rouse, J. Knowledge and power: towards a political philosophy of science. Ithaca: Cornell University Press, 1987.

SANKey, H. Rationality, relativism and incommensurability. Aldershot: Ashgate, 1997.

SAntos, B. S. (Org.). Conhecimento prudente para uma vida decente: um discurso sobre as ciências revisitado. São Paulo: Cortez Editora, 2004.

Another knowledge is possible: beyond northern epistemologies. London: Verso, 2007.

Siegel, H. Incommensurability, rationality and relativism: In science and beyond. In: Hoyningen-Huene, P. \& SANKey, H. (Ed.). Incommensurability and related matters. Dordrecht: Kluwer, 2001. p. 207-24.

TAIT, M. Tecnociência e cientistas: cientificismo e controvérsias na política de biossegurança brasileira. São Paulo: Editora Annablume, 2011c.

TAVEREs, E. D. Da agricultura moderna à agroecologia: análise da sustentabilidade de sistemas agrícolas familiares. Fortaleza: Banco do Nordeste do Brasil/Embrapa, 2009.

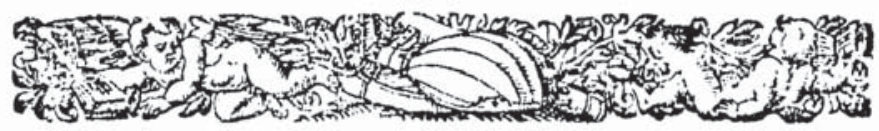

